University of Nebraska - Lincoln

DigitalCommons@University of Nebraska - Lincoln

Center for Brain, Biology and Behavior: Papers \&

Publications

Brain, Biology and Behavior, Center for

4-2016

Oxytocin Receptor (OXTR) Single Nucleotide Polymorphisms

Indirectly Predict Prosocial Behavior through Perspective Taking

and Empathic Concern

Christa C. Christ

Gustavo Carlo

Scott F. Stoltenberg

Follow this and additional works at: https://digitalcommons.unl.edu/cbbbpapers

Part of the Behavior and Behavior Mechanisms Commons, Nervous System Commons, Other Analytical, Diagnostic and Therapeutic Techniques and Equipment Commons, Other Neuroscience and Neurobiology Commons, Other Psychiatry and Psychology Commons, Rehabilitation and Therapy Commons, and the Sports Sciences Commons

This Article is brought to you for free and open access by the Brain, Biology and Behavior, Center for at DigitalCommons@University of Nebraska - Lincoln. It has been accepted for inclusion in Center for Brain, Biology and Behavior: Papers \& Publications by an authorized administrator of DigitalCommons@University of Nebraska Lincoln. 


\title{
Oxytocin Receptor (OXTR) Single Nucleotide Polymorphisms Indirectly Predict Prosocial Behavior through Perspective Taking and Empathic Concern
}

\author{
Christa C. Christ, ${ }^{1}$ Gustavo Carlo, ${ }^{2}$ and Scott F. Stoltenberg ${ }^{1}$
}

1. University of Nebraska-Lincoln, Lincoln, Nebraska, USA

2. University of Missouri, Columbia, Missouri, USA

Corresponding author - Scott F. Stoltenberg, Center for Brain, Biology and Behavior Office C82, East Stadium, University of Nebraska, Lincoln NE, 68588-0156, USA, email sstoltenberg2@unl.edu

\begin{abstract}
Engaging in prosocial behavior can provide positive outcomes for self and others. Prosocial tendencies contribute to the propensity to engage in prosocial behavior.The oxytocin receptor gene (OXTR) has also been associated with prosocial tendencies and behaviors. There has been little research, however, investigating whether the relationship between OXTR and prosocial behaviors is mediated by prosocial tendencies. This relationship may also vary among different types of prosocial behavior. The current study examines the relationship between OXTR, gender, prosocial tendencies, and both altruistic and public prosocial behavior endorsement. Students at a midwestern university $(N=398$; $89.2 \%$ Caucasian; Mage $=20.76 ; 26.6 \%$ male) provided self-report measures of prosocial tendencies and behaviors and buccal cells for genotyping OXTR polymorphisms. Results indicated that OXTR single nucleotide polymorphism (SNP) rs2268498 genotype significantly predicted empathic concern, whereas gender moderated the association between several other OXTR SNPs and prosocial tendencies. Increased prosocial tendencies predicted increased altruistic prosocial behavior endorsement and decreased public prosocial behavior endorsement. Our findings suggest an association between genetic variation in OXTR and endorsement of prosocial behavior indirectly through prosocial tendencies, and that the pathway is dependent on the type of prosocial behavior and gender.
\end{abstract}


Prosocial behavior is defined as voluntary behavior intended to benefit others (Eisenberg, Fabes, \& Spinrad, 2006) and is characterized by behaviors such as sharing and helping others. Prosocial behaviors have been associated with several positive outcomes for the actor, including higher self-esteem (Laible, Carlo, \& Roesch, 2004), academic achievement (Caprara, Barbaranelli, Pastorelli, Bandura, \& Zimbardo, 2000; Miles \& Stipek, 2006), positive social interactions (Farver \& Branstetter, 1994), and social functioning (e.g., constructive social skills, popularity, socially appropriate behavior; Eisenberg et al., 1996). Prosocial behaviors have also been associated with reduced engagement in behaviors such as alcohol and substance use (White, Fleming, Kim, Catalano, \& McMorris, 2008), delinquency and aggression (Carlo, 2006), and racial discrimination (Weyant, 2007). Considering the positive outcomes related to prosocial behavior, it might be beneficial to encourage adolescents to participate in prosocial activities such as community service. For example, a student program that included community service reduced rates of suspension, failing courses, and pregnancy (Allen, Philliber, Herrling, \& Kupermine, 1997). Individuals who engage in prosocial behavior have also been shown to engage in positive activities, such as school extracurricular activities, which decrease school dropout rates and lower the likelihood of being arrested (Mahoney, 2000; Mahoney \& Cairns, 1997). In order to facilitate positive outcomes (i.e., self-esteem, academic achievement, social functioning) of prosocial behavior, it is important to consider the various types of prosocial behavior in addition to understanding each of their unique correlates.

\section{Types of Prosocial Behavior and Their Correlates}

Carlo and Randall (2002) developed a self-report measure to assess multiple types of prosocial behavior: (a) altruistic (i.e., actions intended to primarily benefit others without expectation for self-reward); (b) compliant (i.e., helping others when requested); (c) emotional (i.e., helping others in an emotionally evocative situation); and (d) public (i.e., helping in front of an audience because individuals are potentially motivated by a desire for approval, respect, or increased self-worth). So while some types of prosocial behavior are motivated by internal factors, others are motivated by extrinsic factors (Carlo, 2006; Eisenberg et al., 2006).

Two prominent correlates of prosocial behaviors include the prosocial tendencies: perspective taking (i.e., understanding another's thoughts, feelings, and social situation) and empathic concern (i.e., feelings of sorrow for another's need or distress; Carlo, 2006; Eisenberg et al., 2006). Perspective taking is a sociocognitive trait or skill that usually facilitates prosocial behaviors once an individual understands that a person requires assistance. Furthermore, perspective taking promotes empathic concern for a needy other by allowing the individual to decode his or her situation. Empathic concern reflects a vicariously induced emotional sensitivity that motivates a prosocial behavioral response. Moreover, then, both perspective taking and empathic concern should be positively related to altruistic, but negatively related to public (an egoistic form of helping), prosocial behaviors. Examining the unique contribution of these prosocial tendencies on various prosocial behaviors may help us understand individual differences in engaging in prosocial behavior. 


\section{Contribution of Oxytocin Gene Polymorphisms}

There is accumulating evidence on the genetic and biological basis of prosocial tendencies and behaviors. Indeed, twin studies indicate that genetic factors account for $23-61 \%$ of the variance in prosocial behaviors (Gregory, Light-Hausermann, Rijsdijk, \& Eley, 2009; Knafo, Israel, \& Ebstein, 2011; Lewis \& Bates, 2011). One prominent candidate biological system is oxytocin, which is a neuropeptide broadly implicated in emotional and social processes (Bartz \& Hollander, 2006). Administration of oxytocin facilitates social behavior such as enhancing recognition of emotion in facial expressions and increases the level of in-group trust (see Van Ijzendoorn \& Bakermans-Kranenburg, 2012, for a meta-analysis). Similarly, experiencing greater amounts of empathy increases oxytocin in blood (Barraza \& Zak, 2009). Variation within the gene that encodes the oxytocin receptor (OXTR; located at 3p25) has been associated with prosocial tendencies and prosocial behaviors. Single nucleotide polymorphisms (SNPs) in OXTR (rs237887 and rs4686302) have been associated with emotional empathy (e.g., empathic concern), whereas SNPs rs2268491 and rs2254298 have been associated with cognitive empathy (e.g., perspective taking; $\mathrm{Wu}, \mathrm{Li}, \& \mathrm{Su}, 2012$ ). Furthermore, the associations between OXTR SNPs rs4686302 and rs13316193 and emotional empathy and the combined score of both types of empathy, respectively, were moderated by gender (Wu et al., 2012). Those homozygous for the G allele of SNP rs53576 had higher levels of empathy in both behavioral and self-report measures (Rodrigues, Saslow, Garcia, John, \& Keltner, 2009), and they were also judged to be more prosocial by observers (Kogan et al., 2011). An examination of 15 OXTR SNPs showed that three (rs2268490, rs237887, and rs1042778) were associated with prosocial behaviors using two separate paradigms (Israel et al., 2009). However, when examining males and females separately, three OXTR SNPs (rs237897, rs237887, and rs1042778) were significantly associated with both prosocial paradigms in males, whereas three different OXTR SNPs (rs9840864, rs2268490, and rs237885) were significantly associated with both prosocial paradigms in females (Israel et al., 2009). In sum, there is empirical evidence suggesting that variation in OXTR plays a role in individual differences in prosocial tendencies and prosocial behavior, and that this relationship is moderated by gender.

Although there has been considerable evidence that genetic variation in OXTR is associated with prosocial tendencies and prosocial behaviors, results across specific variants have been mixed. Individuals homozygous for the $G$ allele of rs53576 were judged to be more prosocial than individuals who carried at least one A allele (Kogan et al., 2011); however, no association was found between rs53576 and self-report measures of emotional or cognitive empathy (Wu et al., 2012). The G allele for rs1042778 was associated with higher prosocial responses in a behavioral test compared to the A allele (Israel et al., 2009); there was no association between this SNP and self-report measures of emotional or cognitive empathy (Wu et al., 2012). The G allele of rs 237887 was associated with higher prosocial responses than the A allele (Israel et al., 2009), yet individuals homozygous for the G allele had lower self-reported perspective taking (cognitive empathy) compared to individuals with at least one A allele (Wu et al., 2012). Wu and colleagues (2012) also found that individuals with a G/G genotype for rs237887 had higher self-reported personal distress (emotional empathy) compared to individuals with an $A / G$ genotype, as well as higher fantasy 
(cognitive empathy) compared to individuals with either the A/G or A/A genotype. For rs2254298, in males this SNP is associated with prosocial responses in a behavioral test, although the exact pattern is not described (Israel et al., 2009), but is associated in both males and females with cognitive empathy, such that individuals with an A/G genotype have higher self-report scores compared to those with an A/A genotype (Wu et al., 2012). Continued examination of the association between these polymorphisms and prosocial tendencies and prosocial behaviors would better elucidate their relationship.

\section{Hypotheses}

Although previous studies have tested the association between OXTR gene polymorphisms and both prosocial tendencies and prosocial behavior, to our knowledge there has been no study that investigates the potential mediating effects of prosocial tendencies on the relationship between OXTR gene polymorphisms and various types of prosocial behaviors. This research investigates four interrelated questions. First, is there an association between five selected OXTR SNPs and the prosocial tendencies of empathic concern and perspective taking? Given the mixed findings in previous literature, it is a goal of this research to contribute converging evidence for the contribution of OXTR SNPs on prosocial behaviors and tendencies. Second, is this relationship moderated by gender (given prior demonstrated gender differences in empathy and prosocial behaviors; Carlo, 2006; Eisenberg et al., 2006)? Third, is there an association between five selected OXTR SNPs and both altruistic and public prosocial behaviors? And finally, do perspective taking and empathic concern seven as an intermediate step between OXTR variation and prosocial outcomes? Based on prior research (Carlo, 2006; Eisenberg et al., 2006; Kogan et al., 2011), we hypothesized that OXTR variation would be associated with both perspective taking and empathic concern, which, in turn, would be positively related to altruistic prosocial behaviors and negatively related to public prosocial behaviors.

\section{Method}

\section{Participants}

Undergraduates $(N=398 ; 89.2 \%$ Caucasian) recruited from a midwestern university (Mage $=20.76, S D=3.61 ; 26.6 \%$ male) through the psychology department's subject pool were given course credit for an hour of participation, in which they completed a questionnaire and donated buccal cells for genotyping. The university's Internal Review Board approved this study, and all participants gave written informed consent.

\section{Prosocial Measures}

The prosocial tendencies of empathic concern and perspective taking were measured using the Prosocial Personal Battery (PSB; Penner, Fritzsche, Craiger, \& Freifeld, 1995), which consisted of items from previously developed scales. Items to measure these prosocial tendencies (seven items each) were originally from the Interpersonal Reactivity Index (IRI) and used a 5-point scale ranging from 1 (strongly agree) to 5 (strongly disagree), where lower scores correspond to more prosocial behavior (Davis, 1980, 1983). Sample items include 
"I often have tender, concerned feelings for people less fortunate than me" (empathic concern) and "I try to look at everybody's side of a disagreement before I make a decision" (perspective taking). Items were reverse coded so that higher average scores indicate higher prosocial tendencies. The IRI has demonstrated good test-retest reliability and convergent validity (Davis, 1980). Cronbach's alpha for both of these scales was .78.

Nine items from the Public and Altruistic Prosocial Tendencies Measure (PTM; Carlo \& Randall, 2002) were used to measure two types of prosocial behavior: altruistic helping and public helping. Items were measured on a 5-point scale ranging from 1 (does not describe me at all) to 5 (describes me greatly). Sample items include "I can help others best when people are watching me" (public helping) and "I feel that if I help someone, they should help me in the future" (altruistic helping, reverse coded). Higher average scores indicate higher endorsement for the specific type of prosocial behavior. This measure has been shown to be both valid and reliable (Carlo \& Randall, 2002; Carlo, Hausmann, Christiansen, \& Randall, 2003). Cronbach's alpha for these scales was .83 and .74, respectively.

\section{Genotyping}

DNA was extracted from buccal cells using the PURGENE DNA Isolation Kit Protocol (Qiagen Corp, Valencia, California). OXTR SNPs (rs1042778, rs237887, rs2254298, rs53576, and rs2268498) were genotyped using Taqman SNP Genotyping Assays following the manufacturer's protocol (Applied Biosystems, Foster City, California). Reactions were run on a StepOnePlus Real-Time PCR System, and end point FAM and VIC fluorescence levels were analyzed using ABI Sequence Detection Software v1.2.3 (Applied Biosystems, Foster City, California). These particular SNPs were selected based on either their previous associations with prosocial tendencies and behaviors or their location on the OXTR gene (see Figure 1).

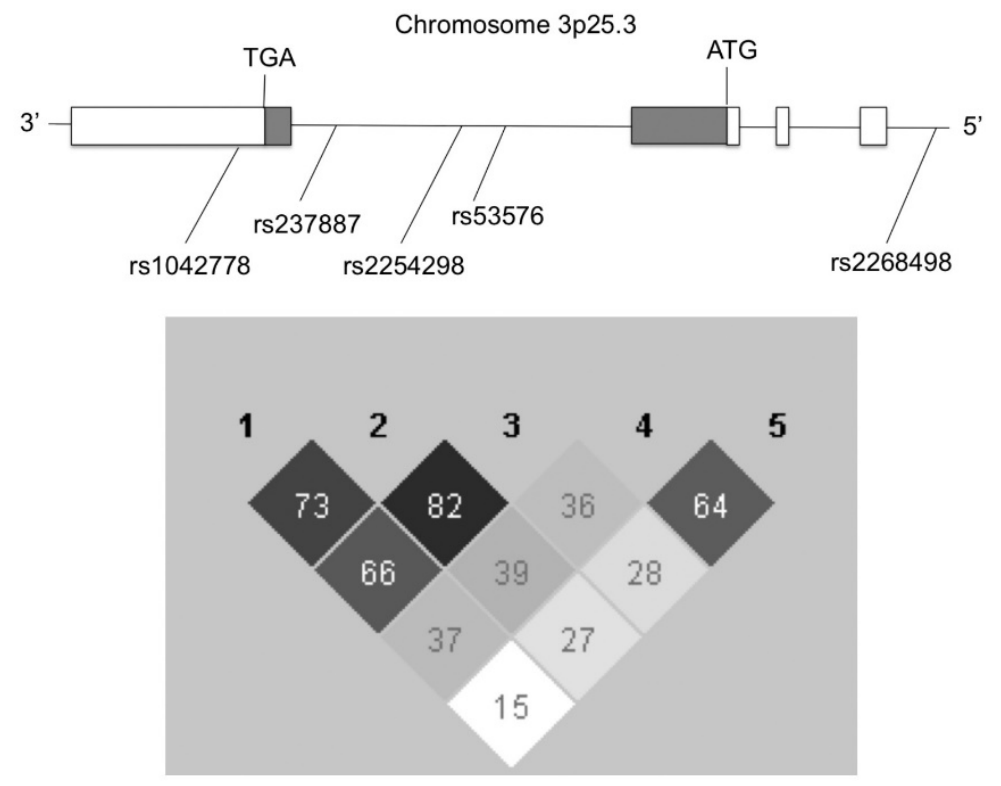

Figure 1. Relative location and Haploview-generated linkage disequilibrium (LD) data ( $\left.\mathrm{D}^{\prime} / \mathrm{LOD}\right)$ for the seven OXTR SNPs tested using the confidence intervals algorithm. 


\section{Statistical Analysis}

Multivariate analysis of covariance (MANCOVA) was used to test the association of gender, OXTR SNP, and their interaction on empathic concern and perspective taking, while controlling for ethnicity (Caucasian vs. non-Caucasian) and age. Since there is not consensus in the literature about the genetic effects of our selected SNPs and since we avoid making assumptions about the genetic effects, association tests were done with three models for each SNP-additive, dominant, and recessive models for the minor allele. Significant associations were then tested for their ability to predict prosocial behaviors using linear regression to perform a path model analysis of manifest variables. Ethnicity (Caucasian vs. non-Caucasian), age, gender, OXTR SNP, and the interaction between gender and the OXTR SNP were entered as the first step in the model. Empathic concern and perspective taking were entered as the intermediate step in the model, followed by prosocial behaviors. Altruistic prosocial behavior and public prosocial behavior were tested independently to examine the potential differences in the model between different types of prosocial behavior. Each OXTR SNP was also put into a separate model to avoid colinearity effects across the SNPs. Data were analyzed with SPSS for Windows (IBM, SPSS Statistics, 21; Chicago, IL). Reported $p$-values are uncorrected for multiple comparisons.

\section{Results}

The average endorsement of public helping prosocial behavior was 1.83 ( $S D=0.76$; range $=1.00-4.25$ ), with higher scores representing a higher endorsement of public helping prosocial behavior. The average endorsement of altruistic helping prosocial behavior was 3.97 $(S D=0.77$; range $=1.60-5.00)$, with higher scores representing a higher endorsement of altruistic helping prosocial behavior. Allele frequencies were all in Hardy-Weinberg Equilibrium and were consistent with previous literature (see Table 1).

\begin{tabular}{lllcl}
\hline \multicolumn{5}{l}{ Table 1. OXTR SNP Allele Frequencies and HardyWeinberg Equilibrium (HWE) } \\
\hline SNP & \multicolumn{2}{c}{ Allele Frequency } & HWE Chi-Square & $p$ \\
\hline rs1042778 & $\mathrm{G}=0.62$ & $\mathrm{~T}=0.38$ & 2.44 & .30 \\
rs237887 & $\mathrm{A}=0.55$ & $\mathrm{G}=0.45$ & 0.67 & .72 \\
rs2254298 & $\mathrm{G}=0.87$ & $\mathrm{~A}=0.13$ & 0.12 & .94 \\
rs53576 & $\mathrm{G}=0.66$ & $\mathrm{~A}=0.34$ & 0.25 & .88 \\
rs2268498 & $\mathrm{T}=0.54$ & $\mathrm{C}=0.46$ & 0.002 & 1.00 \\
\hline
\end{tabular}

Note: $\mathrm{OXTR}=$ oxytocin receptor gene; $\mathrm{SNP}=$ single nucleotide polymorphism

Results of the MANCOVA analyses showed that the only significant genotype main effect was for rs2268498 (T/T vs. C/_) on empathic concern, $F(1,389)=4.552, M S E=.317$, $p=.033$. Those homozygous for the $\mathrm{T}$ allele had significantly higher scores $(M=4.020, S E$ $=.060)$ compared to those carrying a $C$ allele $(M=3.868, S E=.038)$. All other genotype main effects were nonsignificant (see Table 2). 
Table 2. Empathic Concern and Perspective Taking Scores by OXTR SNP Genotypes

\begin{tabular}{|c|c|c|c|c|c|c|c|c|c|c|}
\hline & & Mean & $S E$ & $N$ & $F$ & $p$ & $F$ & $p$ & $F$ & $p$ \\
\hline rs1042778 & & & & & & & \multicolumn{2}{|c|}{ G/G vs.T/_ } & \multicolumn{2}{|c|}{ T/T vs. G_ } \\
\hline \multirow[t]{3}{*}{ Empathic concern } & $\mathrm{G} / \mathrm{G}$ & 3.915 & .050 & 160 & .019 & .981 & .018 & .894 & .035 & .851 \\
\hline & $\mathrm{G} / \mathrm{T}$ & 3.911 & .049 & 170 & & & & & & \\
\hline & $\mathrm{T} / \mathrm{T}$ & 3.896 & .086 & 63 & & & & & & \\
\hline \multirow[t]{3}{*}{ Perspective taking } & G/G & 3.666 & .054 & 160 & .259 & .772 & .079 & .779 & .231 & .631 \\
\hline & $\mathrm{G} / \mathrm{T}$ & 3.706 & .052 & 170 & & & & & & \\
\hline & $\mathrm{T} / \mathrm{T}$ & 3.639 & .092 & 63 & & & & & & \\
\hline \multicolumn{7}{|l|}{ rs237887 } & \multicolumn{2}{|c|}{ A/A vs. G/_ } & \multicolumn{2}{|c|}{ G/G vs. A/_ } \\
\hline \multirow[t]{3}{*}{ Empathic concern } & $\mathrm{A} / \mathrm{A}$ & 3.861 & .060 & 124 & 1.136 & .322 & 1.127 & .289 & .424 & .515 \\
\hline & $\mathrm{A} / \mathrm{G}$ & 3.963 & .046 & 189 & & & & & & \\
\hline & $\mathrm{G} / \mathrm{G}$ & 3.874 & .070 & 85 & & & & & & \\
\hline \multirow[t]{3}{*}{ Perspective taking } & $\mathrm{A} / \mathrm{A}$ & 3.715 & .063 & 124 & 1.412 & .245 & .442 & .506 & 2.818 & .094 \\
\hline & $\mathrm{A} / \mathrm{G}$ & 3.705 & .049 & 189 & & & & & & \\
\hline & $\mathrm{G} / \mathrm{G}$ & 3.569 & .074 & 85 & & & & & & \\
\hline \multicolumn{7}{|l|}{ rs2254298 } & \multicolumn{2}{|c|}{ G/G vs.A_ } & \multicolumn{2}{|c|}{ A/A vs. G/_ } \\
\hline \multirow[t]{3}{*}{ Empathic concern } & $\mathrm{G} / \mathrm{G}$ & 3.936 & .037 & 296 & 1.744 & .176 & 2.723 & .100 & 1.573 & .211 \\
\hline & G/A & 3.821 & .074 & 92 & & & & & & \\
\hline & $\mathrm{A} / \mathrm{A}$ & 3.616 & .237 & 7 & & & & & & \\
\hline \multirow[t]{3}{*}{ Perspective taking } & $\mathrm{G} / \mathrm{G}$ & 3.704 & .039 & 296 & 1.951 & .144 & 2.832 & .093 & 2.086 & .149 \\
\hline & G/A & 3.584 & .079 & 92 & & & & & & \\
\hline & $\mathrm{A} / \mathrm{A}$ & 3.311 & .254 & 7 & & & & & & \\
\hline \multicolumn{7}{|l|}{ rs53576 } & \multicolumn{2}{|c|}{ G/G vs. A/_ } & \multicolumn{2}{|c|}{ A/A vs. G/_ } \\
\hline \multirow[t]{3}{*}{ Empathic concern } & $\mathrm{G} / \mathrm{G}$ & 3.883 & .049 & 174 & .719 & .488 & .676 & .411 & .339 & .561 \\
\hline & $\mathrm{G} / \mathrm{A}$ & 3.955 & .047 & 171 & & & & & & \\
\hline & $\mathrm{A} / \mathrm{A}$ & 3.862 & .097 & 47 & & & & & & \\
\hline \multirow[t]{3}{*}{ Perspective taking } & $\mathrm{G} / \mathrm{G}$ & 3.665 & .054 & 174 & .059 & .943 & .094 & .759 & .002 & .966 \\
\hline & G/A & 3.690 & .052 & 171 & & & & & & \\
\hline & $\mathrm{A} / \mathrm{A}$ & 3.672 & .106 & 47 & & & & & & \\
\hline \multicolumn{7}{|l|}{ rs2268498 } & \multicolumn{2}{|c|}{ T/T vs. C/_ } & \multicolumn{2}{|c|}{ C/C vs.T/_ } \\
\hline \multirow[t]{3}{*}{ Empathic concern } & $\mathrm{T} / \mathrm{T}$ & 4.020 & .060 & 114 & 2.386 & .093 & 4.552 & .033 & 1.380 & .241 \\
\hline & $\mathrm{T} / \mathrm{C}$ & 3.882 & .046 & 196 & & & & & & \\
\hline & $\mathrm{C} / \mathrm{C}$ & 3.839 & .068 & 85 & & & & & & \\
\hline \multirow[t]{3}{*}{ Perspective taking } & $\mathrm{T} / \mathrm{T}$ & 3.675 & .065 & 114 & 1.278 & .280 & .000 & .984 & 2.273 & .132 \\
\hline & $\mathrm{T} / \mathrm{C}$ & 3.720 & .049 & 196 & & & & & & \\
\hline & $\mathrm{C} / \mathrm{C}$ & 3.578 & .074 & 85 & & & & & & \\
\hline
\end{tabular}

Note: $\mathrm{OXTR}=$ oxytocin receptor gene; $\mathrm{SNP}=$ single nucleotide polymorphism

There was a significant interaction between gender and rs237887 with the full genotype model on perspective taking, $F(2,390)=4.370, M S E=.366, p=.013$. A significant interaction was also found for perspective taking when those who were homozygous for the A allele were grouped with those who had a heterozygous genotype, $F(1,392)=8.763, M S E=.364$, $p=.003$. There was also a marginally significant interaction between gender and rs1042778 with the full genotype model on perspective taking, $F(2,385)=3.043, M S E=.367, p=.049$. Finally, for rs2254298, when those who were homozygous for the A allele were grouped with those who were heterozygous, there was a significant interaction with gender on both 
empathic concern, $F(1,389)=6.265, M S E=.319, p=.013$, and perspective taking, $F(1,389)=$ $6.217, M S E=.368, p=.013$. The patterns of the interactions on perspective taking and empathic concern are displayed in Figure 2 and Figure 3, respectively.

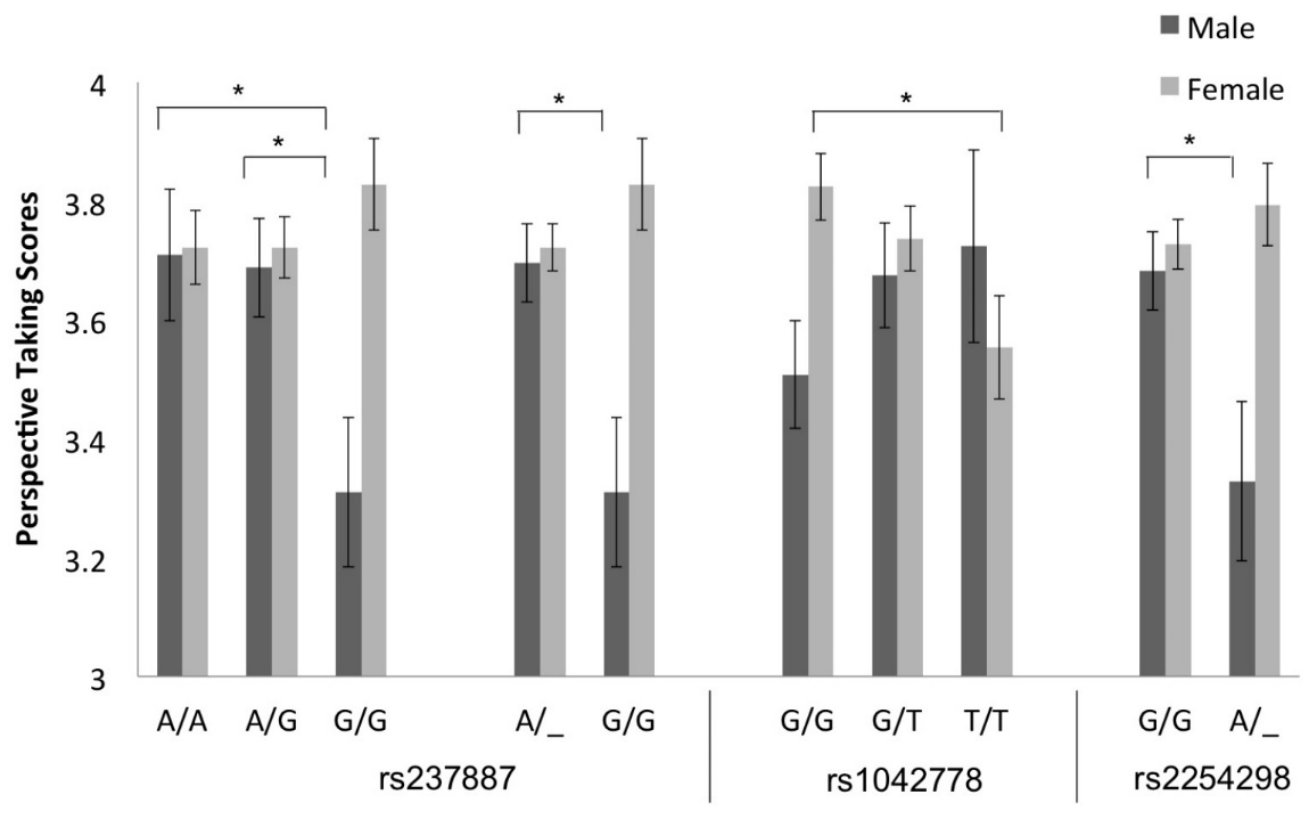

Figure 2. Interaction pattern between OXTR SNPs and gender on perspective taking. There was a significant interaction between gender and (a) rs237887 (both the additive and recessive models), (b) rs1042778 (additive model), and (c) rs2254298 (dominant model) on perspective taking. For rs237887, males with a G/G genotype had significantly lower perspective taking scores compared to males with either $\mathrm{A} / \mathrm{A}$ or $\mathrm{A} / \mathrm{G}$ genotypes. For rs1042778, females with a T/T genotype had significantly lower perspective taking scores compared to females with a G/G genotype. For rs2254298, males with at least one A allele have significantly lower perspective taking scores compared to males who are homozygous for the $\mathrm{G}$ allele. 


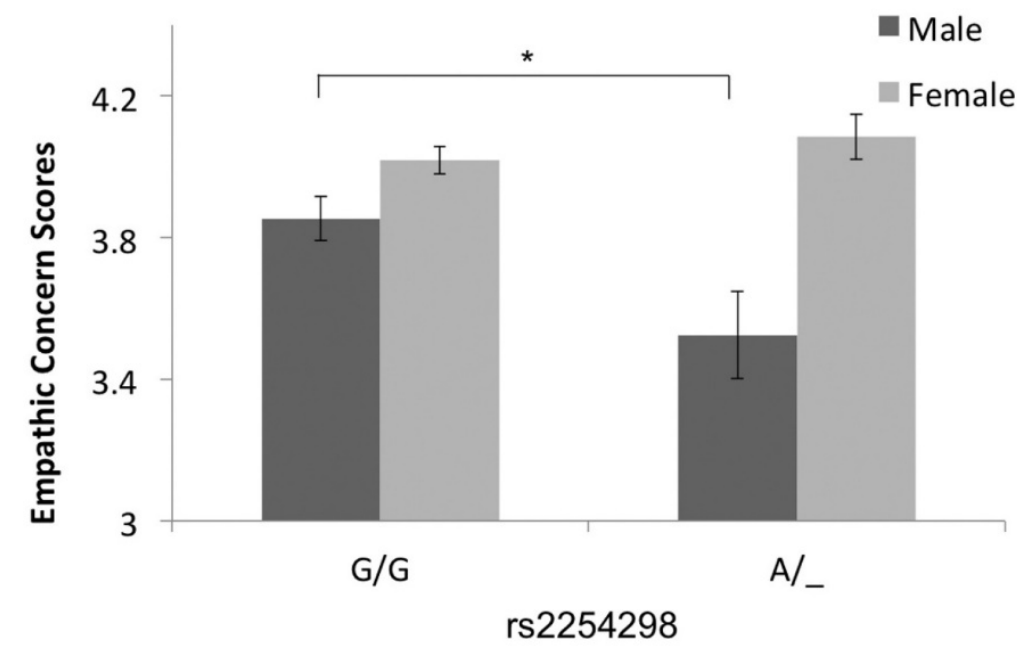

Figure 3. Interaction pattern between rs2254298 and gender on empathic concern. For rs2254298, males with at least one A allele have significantly lower empathic concern scores compared to males who are homozygous for the $G$ allele.

Linear regression was then used to investigate whether significant associations between gender, OXTR SNP, and their interaction on prosocial tendencies were predictive of the endorsement of altruistic and public helping behaviors. Perspective taking and empathic concern were predicted by gender, OXTR SNP, and their interaction in a pattern consistent with the MANCOVA results (see Tables 3-6). For rs2268498, empathic concern predicted endorsement of both altruistic and public helping behavior, such that an increase in empathic concern resulted in increased endorsement of altruistic helping and decreased endorsement of public helping behavior. For the interactions of (a) rs237887 and gender, (b) rs1042778 and gender, as well as (c) rs2254298 and gender, perspective taking predicted endorsement of both altruistic and public helping behavior, such that an increase in empathic concern resulted in increased endorsement of altruistic helping and decreased endorsement of public helping behavior. For the interaction of rs2254298 and gender, empathic concern also predicted the endorsement of altruistic helping behavior, such that an increase in empathic concern resulted in increased endorsement of altruistic helping behavior. There was no direct effect of each OXTR SNP on the endorsement of either altruistic or public helping. 
Table 3. Regression Analysis with Age, Ethnicity, Gender, rs2268498 (T/T vs. C/_), and Empathic Concern Predicting the Endorsement of Altruistic and Public Helping Behavior

\begin{tabular}{|c|c|c|c|c|c|c|}
\hline Criterion & \multicolumn{2}{|c|}{ Empathic Concern } & \multicolumn{2}{|c|}{ Altruistic Helping } & \multicolumn{2}{|c|}{ Public Helping } \\
\hline Predictor & $b(S E)$ & $\beta$ & $b(S E)$ & $\beta$ & $b(S E)$ & $\beta$ \\
\hline Intercept & $3.845(.185)$ & - & $1.653(.347)$ & - & $3.344(.353)$ & - \\
\hline Age & $.004(.008)$ & .023 & $.040(.010)^{* * *}$ & .186 & $-.032(.010)^{* *}$ & -.152 \\
\hline Ethnicity & $-.022(.092)$ & -.012 & $.173(.119)$ & .069 & $-.014(.121)$ & -.006 \\
\hline Gender & $.234(.064)^{* * *}$ & .180 & $.183(.084)^{*}$ & .105 & $-.182(.086)^{*}$ & -.107 \\
\hline rs2268498 (T/T vs. C/_) & $-.172(.063)^{* *}$ & -.135 & $.023(.082)$ & .013 & $-.037(.083)$ & -.022 \\
\hline Empathic concern & - & - & $.337(.065)^{* * *}$ & .251 & $-.174(.067)^{*}$ & -.132 \\
\hline
\end{tabular}

Note: ${ }^{*} p<.05,{ }^{* *} p<.01,{ }^{* * *} p<.001$

Table 4. Regression Analysis with Age, Ethnicity, Gender, rs237887, Gender $\times$ SNP Interaction, and Perspective Taking Predicting the Endorsement of Altruistic and Public Helping Behavior

\begin{tabular}{|c|c|c|c|c|c|c|}
\hline \multirow{2}{*}{$\begin{array}{l}\text { Criterion } \\
\text { Predictor }\end{array}$} & \multicolumn{2}{|c|}{ Perspective Taking } & \multicolumn{2}{|c|}{ Altruistic Helping } & \multicolumn{2}{|c|}{ Public Helping } \\
\hline & $b(S E)$ & $\beta$ & $b(S E)$ & $\beta$ & $b(S E)$ & $\beta$ \\
\hline \multicolumn{7}{|l|}{ Additive model } \\
\hline Intercept & $3.411(.207)$ & - & $1.874(.322)$ & - & $3.241(.327)$ & - \\
\hline Age & $.017(.008)^{*}$ & .101 & $.035(.010)^{* *}$ & .163 & $-.028(.010)^{* *}$ & -.133 \\
\hline Ethnicity & $.171(.098)$ & .087 & $.130(.118)$ & .052 & $.012(.119)$ & .005 \\
\hline Gender & $-.086(.113)$ & -.062 & $.337(.135)^{*}$ & .194 & $-.182(.134)$ & -.107 \\
\hline rs237887 (G/G vs. A/_) & $-.188(.084)^{*}$ & -.220 & $.043(.101)$ & .040 & $-.072(.102)$ & .068 \\
\hline rs 237887 × Gender & $.236(.097)^{*}$ & .282 & $-.128(.117)$ & -.122 & $-.016(.118)$ & -.015 \\
\hline Perspective taking & - & - & $.317(.060)^{* * *}$ & .253 & $-.204(.061)^{* *}$ & -.166 \\
\hline \multicolumn{7}{|l|}{ GG vs. A } \\
\hline Intercept & 3.327 (.192) & - & $1.901(.307)$ & - & $3.273(.311)$ & - \\
\hline Age & $.017(.008)^{*}$ & .099 & $.035(.010)^{* *}$ & .165 & $-.028(.010)^{* *}$ & -.134 \\
\hline Ethnicity & $.178(.098)$ & .090 & $.127(.118)$ & .051 & $.013(.120)$ & .005 \\
\hline Gender & $.026(.077)^{* *}$ & .019 & $.248(.093)^{* *}$ & .143 & $-.180(.094)$ & -.105 \\
\hline rs237887 (G/G vs. A/_) & $-.386(.142)^{* *}$ & -.258 & $.059(.173)$ & .031 & $.133(.175)$ & .072 \\
\hline rs237887 × Gender & $.492(.166)^{* *}$ & .291 & $-.120(.203)$ & -.057 & $-.090(.205)$ & -.043 \\
\hline Perspective taking & - & - & $.314(.061)^{* * *}$ & .251 & $-.201(.062)^{* *}$ & -.164 \\
\hline
\end{tabular}

Note: ${ }^{*} p<.05,{ }^{* *} p<.01,{ }^{* * *} p<.001$ 
Table 5. Regression Analysis with Age, Ethnicity, Gender, rs1042778, Gender * SNP Interaction, and Perspective Taking Predicting the Endorsement of Altruistic and Public Helping Behavior

\begin{tabular}{|c|c|c|c|c|c|c|}
\hline Criterion & \multicolumn{2}{|c|}{ Perspective Taking } & \multicolumn{2}{|c|}{ Altruistic Helping } & \multicolumn{2}{|c|}{ Public Helping } \\
\hline Predictor & $b(S E)$ & $\beta$ & $b(S E)$ & $\beta$ & $b(S E)$ & $\beta$ \\
\hline Intercept & $3.098(.199)$ & - & $1.941(.304)$ & - & $3.397(.310)$ & - \\
\hline Age & $.020(.009)^{*}$ & .115 & $.033(.010)^{* *}$ & .156 & $-.029(.010)^{* *}$ & -.137 \\
\hline Ethnicity & $.165(.098)$ & .084 & $.136(.118)$ & .055 & $.088(.120)$ & .003 \\
\hline Gender & $.314(.100)^{* *}$ & .226 & $.146(.121)$ & .084 & $-.258(.124)^{*}$ & -.151 \\
\hline rs1042778 & $.124(.086)$ & .144 & $-.033(.103)$ & -.030 & $-.120(.105)$ & -.122 \\
\hline rs1042778 × Gender & $-.250(.099)^{*}$ & -.286 & $.113(.120)$ & .103 & $.084(.122)$ & .078 \\
\hline Perspective taking & - & - & $.322(.061)^{* * *}$ & .258 & $-.200(.062)^{* *}$ & -.163 \\
\hline
\end{tabular}

Note: ${ }^{*} p<.05,{ }^{* *} p<.01,{ }^{* * *} p<.001$

Table 6. Regression Analysis with Age, Ethnicity, Gender, rs2254298 (G/G vs. A/_), Gender × SNP Interaction, and Perspective Taking Predicting the Endorsement of Altruistic and Public Helping Behavior

\begin{tabular}{|c|c|c|c|c|c|c|c|c|}
\hline \multirow{2}{*}{$\begin{array}{l}\text { Criterion } \\
\text { Predictor }\end{array}$} & \multicolumn{2}{|c|}{ Empathic Concern } & \multicolumn{2}{|c|}{ Perspective Taking } & \multicolumn{2}{|c|}{ Altruistic Helping } & \multicolumn{2}{|c|}{ Public Helping } \\
\hline & $b(S E)$ & $\beta$ & $b(S E)$ & $\beta$ & $b(S E)$ & $\beta$ & $b(S E)$ & $\beta$ \\
\hline Intercept & $3.725(.176)$ & - & $3.254(.189)$ & - & $1.385(.342)$ & - & $3.502(.350)$ & - \\
\hline Age & $.006(.008)$ & .038 & $.020(.009)^{*}$ & .114 & $.035(.010)^{* *}$ & .162 & $-.030(.010)^{* *}$ & -.141 \\
\hline Ethnicity & $.027(.092)$ & .015 & $.192(.099)$ & .097 & $.160(.117)$ & .065 & $-.028(.120)$ & -.011 \\
\hline Gender & $.166(.073)^{*}$ & .128 & $.044(.078)$ & .032 & $.227(.093)^{*}$ & .131 & $-.197(.095)^{*}$ & -.115 \\
\hline rs2254298 & $-.328(.139)^{*}$ & -.247 & $-.354(.149)^{*}$ & -.249 & $.052(.178)$ & .029 & $.186(.182)$ & .106 \\
\hline rs2254298 × Gender & $.394(.157)^{*}$ & .272 & $.422(.169)^{*}$ & .273 & $-.180(.202)$ & -.093 & $-.005(.206)$ & -.003 \\
\hline Empathic concern & - & - & - & - & $.234(.072)^{* *}$ & .176 & $-.087(.074)$ & -.066 \\
\hline Perspective taking & - & - & - & - & $.213(.067)^{* *}$ & .171 & $-.166(.068)^{*}$ & -.135 \\
\hline
\end{tabular}

Note: ${ }^{*} p<.05{ }^{* *} p<.01 .{ }^{* * *} p<.001$

\section{Discussion}

The main finding of this study is that variation in OXTR SNPs (specifically, rs2268498, rs237887, rs1042778, and rs2254298) was indirectly associated with prosocial behaviors via empathic concern and perspective taking tendencies, and that these effects were moderated by gender. These are the first known findings that delineate a mediating mechanism between the oxytocin system and prosocial behaviors through sociocognitive and socioemotive traits. Although prior research suggests an association between OXTR and prosocial behaviors, the present findings extend those findings and suggest the association is primarily indirect. These findings add to the accumulating evidence on a genetic basis for prosocial behaviors and extend such evidence to show that OXTR can predict both selfless and selfish forms of prosocial behaviors. Although further research is needed to replicate the present findings, this is a first step toward delineating more complex pathways between genes and different forms of prosocial behaviors. 
Whereas altruistic prosocial behavior is selflessly motivated, public prosocial behavior is selfishly motivated (see Carlo, 2006). Our results, which indicate that higher levels of empathic concern and perspective taking are associated with higher endorsement of altruistic prosocial behavior, are consistent with the notion that such behavior is selflessly motivated. Several scholars have noted overall positive relations between both sociocognitive and socioemotive traits and prosocial behaviors (Eisenberg et al., 2006). However, prior research has often not distinguished between other forms of prosocial behaviors and altruistic forms - the present findings suggest that these traits are generally associated with this selfless form of prosocial behavior. Moreover, although researchers have suggested that perspective taking can sometimes be used to take advantage or harm others (Feshbach, 1987), meta-analytic reviews of the research literature show an overall positive relation between this sociocognitive trait and prosocial behaviors (Carlo, 2006).

In contrast, lower perspective taking scores were associated with higher endorsement of public prosocial behavior. A possible explanation for this finding could be due to the focus on one's self rather than to taking the perspective of others. Individuals who are less prone to think about the situation of others may be more focused on themselves and help only if they deem some advantage (e.g., gain popularity or social status) for themselves in helping others. Prior research suggests that individuals who frequently engage in prosocial behaviors in public have a desire to gain other people's approval (Carlo \& Randall, 2002). Furthermore, perspective taking is negatively associated with aggression and delinquency (Carlo, Köller, \& Eisenberg, 1998; Miller \& Eisenberg, 1988). Taken together, these findings are in accord with the notion that perspective taking generally results in selfless forms, and less selfish forms, of prosocial behaviors.

Although only a small number of studies have been published regarding OXTR SNP rs2268498, our findings are consistent with this literature. We found that those with a T/T genotype had significantly higher empathic concern scores compared to those carrying an A allele. Melchers, Montag, Markett, and Reuter (2013) found that carrying at least one T allele (both $\mathrm{T} / \mathrm{T}$ and $\mathrm{C} / \mathrm{T}$ genotypes) was associated with higher emotion detection accuracy compared to those with an A/A genotype. This ability to interpret the emotional expressions of others is an important precursor in prosocial tendencies (Lamm, Batson, \& Decety, 2007). The T/T genotype has also been associated with lower negative emotionality when combined with the L/L genotype of 5-HTTLPR (Montag, Fiebach, Kirsch, \& Reuter, 2011). Lower negative emotionality, in turn, is associated with prosocial reputations in children (Eisenberg et al., 1996).

Previous literature is also limited regarding the association between rs237887 and prosocial tendencies and behaviors. The A allele has been associated with higher levels of perspective taking (Wu et al., 2012), whereas the $\mathrm{G}$ allele has been associated with prosocial responses in a behavioral paradigm, particularly in males (Israel et al., 2009). The G/G genotype is also associated with higher personal distress and fantasy scores (Wu et al., 2012). It is interesting that both perspective taking and fantasy are both considered cognitive aspects, and yet the association with this SNP is the opposite for these two subscales. $\mathrm{Wu}$ and colleagues (2012) also reported no significant interaction between rs237887 and prosocial tendencies. We found that the $\mathrm{G} / \mathrm{G}$ genotype is associated with lower levels of perspective 
taking, which is consistent with the findings of $\mathrm{Wu}$ and colleagues (2012); however, we found this pattern only in males.

Our finding that the G/G genotype for rs1042778 is associated with higher perspective taking scores compared to the $\mathrm{T} / \mathrm{T}$ genotype is consistent with previous literature. The $\mathrm{T} / \mathrm{T}$ genotype has been associated with lower empathic communication when included in an OXTR cumulative risk score (Schneiderman, Kanat-Maymon, Ebstein, \& Feldman, 2014). The $\mathrm{T}$ allele is also associated with lower prosocial responses in a behavioral paradigm (Israel et al., 2009); however, when examining this relationship by gender groups, Israel and colleagues found that this pattern was only significant in males, whereas our results were found only in females.

For rs2254298, the G/G genotype is associated with more social behavior; adolescent Caucasian girls with the A/G genotype (compared to $G / G$ ) who had experienced high early adversity reported the highest levels of social anxiety (Thompson, Parker, Hallmayer, Waugh, \& Gotlib, 2011). In another adolescent sample, social loneliness was lower in individuals with the G/G genotype (Lucht et al., 2009). Individuals carrying an A allele recognized positive facial emotional expressions less frequently than $\mathrm{G}$ homozygotes (Lucht et al., 2013). Although our findings appear to be supported by this previous empirical literature, there are several studies that were found to be inconsistent with our results.

Contrary to our findings, $\mathrm{Wu}$ and colleagues (2012) found higher reported cognitive empathy in Chinese participants with a G/A genotype compared to an A/A genotype, and no difference between either of these groups compared to $G / G$ individuals. Although this previous study also used the IRI scale that was used in our study, Wu et al. (2012) combined perspective taking and fantasy (not measured in our study) subscales as one cognitive empathy subscale, which may account for some of the differences in our results. Another study using the IRI scale found that individuals with schizophrenia carrying an A allele had higher empathic concern compared to $G / G$ individuals, but there was no difference found among healthy controls (Montag et al., 2012). Our association between rs2254298 and prosocial tendencies was also observed only in males, and to our knowledge, only one other study examined the moderating effect of gender on this relationship (Wu et al., 2012). Our results were inconsistent with their study in that $\mathrm{Wu}$ and colleagues found no moderating effect of gender on rs2254298. Inconsistencies in the results between $\mathrm{Wu}$ and colleagues and our findings may also be a result of differences in allele frequencies between a Caucasian $(\mathrm{G}=.93)$ and Han Chinese $(\mathrm{G}=.71)$ population.

Although the exact function of rs2254298 is not known, the A allele is associated with larger bilateral amygdala volume (Inoue et al., 2010). This finding was further supported by Furman and colleagues, who showed that the G/G genotype has been associated with smaller left and right amygdala volume compared to individuals with the A/G genotype (Furman, Chen, \& Gotlib, 2011), suggesting that this SNP may be functional because smaller amygdala volume has been associated with increased neural activation to emotionally valenced stimuli (Kalmar et al., 2009). Amygdala volume is positively correlated with the size and complexity of social groupings in humans (Bickart, Wright, Dautoff, Dickerson, \& Barrett, 2011) and social play frequency in nonhuman primates (Lewis \& Barton, 2006). The $G / G$ genotype is also associated with lower plasma oxytocin compared to those with an A allele (Feldman et al., 2012). From these findings, we might expect that the 
A allele would be associated with prosocial behavior; however, our findings suggested the opposite pattern of association. Evidence by Tost and colleagues (2011) showed that gender moderated the association between rs2254298 and hypothalamus gray matter volume in a Caucasian population such that males with a G/G genotype had higher hypothalamus gray matter volume. This group also found that those with larger hypothalamus gray matter volume had great reward dependence, suggesting that these individuals would be less socially detached and therefore more prosocial (Tost et al., 2010). Together with our findings, we hypothesize that the larger hypothalamus gray matter volume observed in males with a $\mathrm{G} / \mathrm{G}$ genotype may be important in prosocial tendencies and subsequent prosocial behavior.

Our findings should be interpreted in light of certain limitations. Due to the use of a correlational design with self-report measures, we cannot make any conclusions regarding causal relationships; therefore, it would be beneficial to examine this relationship using experimental methodologies. Additionally, our sample was primarily Caucasian in ancestry with a limited age range, so results should be considered cautiously as they may not generalize to other populations.

Given the long-term social implications of understanding individual differences in prosocial behavior, it is important to develop more comprehensive models of the genetic contributions to individual differences in the propensity to engage in such behaviors. Our findings suggest that variation within the OXTR gene partially explains individual differences in prosocial behaviors, particularly in males. We also show that the pathway between OXTR and prosocial behaviors varies depending on the type of prosocial behavior, indicating that future efforts to determine contributing factors to such behavior should consider the various types of prosocial behavior.

Declaration of Conflicting Interests - The authors declare no potential conflicts of interest with respect to the research, authorship, and/or publication of this article.

Funding - The authors disclose receipt of the following financial support for the research, authorship, and/or publication of this article: Preparation of this article was supported by a Faculty Research Seed Grant from UNL Research Council (SFS).

\section{References}

Allen, J. P., Philliber, S., Herrling, S., \& Kupermine, G. P. (1997). Preventing teen pregnancy and academic failure: Experimental evaluation of a developmentally based approach. Child Development, 68, 729-742.

Barraza, J. A., \& Zak, P. J. (2009). Empathy toward strangers triggers oxytocin release and subsequent generosity. Annals of the New York Academy of Sciences, 1167, 182-189.

Bartz, A. J., \& Hollander, E. (2006). The neuroscience of affiliation: Forging links between basic and clinical research on neuropeptides and social behavior. Hormones and Behavior, 50, 518-528.

Bickart, K. C., Wright, C. I., Dautoff, R. J., Dickerson, B. C., \& Barrett, L. F. (2011). Amygdala volume and social network size in humans. Nature Neuroscience, 14, 163-164.

Caprara, G. V., Barbaranelli, C., Pastorelli, C., Bandura, A., \& Zimbardo, P. G. (2000). Prosocial foundations of children's academic achievement. Psychological Science, 11, 302-306. 
Carlo, G. (2006). Care-based and altruistically-based morality. In M. Killen \& J. G. Smetana (Eds.), Handbook of moral development (pp. 551-579). Mahwah, NJ: Erlbaum.

Carlo, G., Hausmann, A., Christiansen, S., \& Randall, B. A. (2003). Sociocognitive and behavioral correlates of a measure of prosocial tendencies for adolescents. Journal of Early Adolescence, 23, $107-134$.

Carlo, G., Köller, S., \& Eisenberg, N. (1998). Prosocial moral reasoning in institutionalized delinquent, orphaned, and noninstitutionalized Brazilian adolescents. Journal of Adolescent Research, 13, 363-376.

Carlo, G., \& Randall, B. A. (2002). The development of a measure of prosocial behaviors for late adolescents. Journal of Youth and Adolescence, 31, 31-44.

Davis, M. H. (1980). A multidimensional approach to individual differences in empathy. JSAS Catalog of Selected Documents in Psychology, 10, 85.

Davis, M. H. (1983). Measuring individual differences in empathy: Evidence for a multidimensional approach. Journal of Personality and Social Psychology, 44, 113-126.

Eisenberg, N., Fabes, R. A., Karbon, M., Murphy, B. C., Wosinkski, M., Polazzi, L., et al. (1996). The relations of children's dispositional prosocial behavior to emotionality, regulation, and social functioning. Child Development, 67, 974-992.

Eisenberg, N., Fabes, R. A., \& Spinrad, T. I. (2006). Prosocial development. In W. Damon \& R. M. Lerner (Series Eds.) \& N. Eisenberg (Vol. Ed.), Handbook of child psychology: Vol. 3. Social, emotional, and personality development (6th ed., pp. 646-718). New York: Wiley.

Farver, J. M., \& Branstetter, W. H. (1994). Preschoolers' prosocial responses to their peers' distress. Developmental Psychology, 30, 334-341.

Feldman, R., Zagoory-Sharon, O., Weisman, O., Schneiderman, I., Gordon, I., Maoz, R., et al. (2012). Sensitive parenting is associated with plasma oxytocin and polymorphisms in the OXTR and CD38 genes. Biological Psychiatry, 72, 175-181.

Feshbach, N. D. (1987). Parental empathy and child adjustment/maladjustment. In N. Eisenberg \& J. Strayer (Eds.), Empathy and Its Development. New York: Cambridge University Press.

Furman, D. J., Chen, M. C., \& Gotlib, I. H. (2011). Variant in oxytocin receptor gene is associated with amygdala volume. Psychoneuroendocrinology, 36, 891-897.

Gregory, A. M., Light-Hausermann, J. H., Rijsdijk, F., \& Eley, T. C. (2009). Behavioral genetic analyses of prosocial behavior in adolescents. Developmental Science, 12, 165-174.

Inoue, H., Yamasue, H., Tochigi, M., Abe, O., Liu, X., Kawamura, Y., et al. (2010). Association between the oxytocin receptor gene and amygdalar volume in healthy adults. Biological Psychiatry, 68, 1066-1072.

Israel, S., Lerer, E., Shalev, I., Uzefovsky, F., Riebold, M., Laiba, E., et al. (2009). The oxytocin receptor (OXTR) contributes to prosocial fund allocations in the dictator game and the social value orientations task. PLoS ONE, 4, e5535.

Kalmar, J. H., Wang, F., Chepenik, L. G., Womer, F.Y., Jones, M. M., Pittman, B., et al. (2009). Relation between amygdala structure and function in adolescents with bipolar disorder. Journal of the American Academy of Child and Adolescent Psychiatry, 48, 636-642.

Knafo, A., Israel, S., \& Ebstein, R. P. (2011). Heritability of children's prosocial behavior and differential susceptibility to parenting by variation in the dopamine receptor D4 gene. Development and Psychopathology, 23, 53-67.

Kogan, A., Saslow, L. R., Impett, E. A., Oveis, C., Keltner, D., \& Saturn, S. R. (2011). Thin-slicing study of the oxytocin receptor (OXTR) gene and the evaluation and expression of the prosocial disposition. Proceedings of the National Academy of Sciences, 108, 19189-19192. 
Laible, D. J., Carlo, G., \& Roesch, S. C. (2004). Pathways to self-esteem in late adolescence: The role of parent and peer attachment, empathy, and social behaviors. Journal of Adolescence, 27, 703-716.

Lamm, C., Batson, C. D., \& Decety, J. (2007). The neural substrate of human empathy: Effects of perspectivetaking and cognitive appraisal. Journal of Cognitive Neuroscience, 19, 42-58.

Lewis, K. P., \& Barton, R. A. (2006). Amygdala size and hypothalamus size predict social play frequency in nonhuman primates: A comparative analysis using independent contrasts. Journal of Comparative Psychology, 120, 31-37.

Lewis, G. J., \& Bates, T. C. (2011). A common heritable factor influences prosocial obligations across multiple domains. Biology Letters, 7, 567-570.

Lucht, M. J., Barnow, S., Sonnenfeld, C., Rosenberger, A., Grabe, H. J., Schroeder, W., et al. (2009). Association between the oxytocin receptor gene (OXTR) and affect, loneliness and intelligence in normal subjects. Progress in Neuro-Psychopharmacology \& Biological Psychiatry, 33, 860-866.

Lucht, M. J., Barnow, S., Sonnenfeld, C., Ulrich, I., Grabe, H. J., Schroder, W., et al. (2013). Associations between the oxytocin receptor gene (OXTR) and "mind-reading" in humans-An exploratory study. Nordic Journal of Psychiatry, 67, 15-21.

Mahoney, J. L. (2000). School extracurricular activity participation as a moderator in the development of antisocial patterns. Child Development, 71, 502-516.

Mahoney, J., \& Cairns, R. (1997). Do extracurricular activities protect against early school dropout? Developmental Psychology, 33, 241-253.

Melchers, M., Montag, C., Markett, S., \& Reuter, M. (2013). Relationship between oxytocin receptor genotype and recognition of facial emotion. Behavioral Neuroscience, 127, 780-787.

Miles, S. B., \& Stipek, D. (2006). Contemporaneous and longitudinal associations between social behavior and literacy achievement in a sample of low-income elementary school children. Child Development, 77, 103-117.

Miller, P. A., \& Eisenberg, N. (1988). The relation of empathy to aggression and externalizing/antisocial behavior. Psychological Bulletin, 103, 324-344.

Montag, C., Brockmann, E. M., Lehmann, A., Muller, D. J., Rujescu, D., \& Gillinat, J. (2012). Association between oxytocin receptor gene polymorphisms and self-rated 'empathic concern' in schizophrenia. PLoS ONE, 7, e51882.

Montag, C., Fiebach, C. J., Kirsch, P., \& Reuter, M. (2011). Interaction of 5-HTTLPR and a variation on the oxytocin receptor gene influences negative emotionality. Biological Psychiatry, 69, 601-603.

Penner, L. A., Fritzsche, B. A., Craiger, J. P., \& Freifeld, T. R. (1995). Measuring the prosocial personality. In J. Butcher \& C. D. Speilberger (Eds.), Advances in personality assessment (Vol. 10, pp. 147163). Hillsdale, NJ: Erlbaum.

Rodrigues, S. M., Saslow, L. R., Garcia, N., John, O. P., \& Keltner, D. (2009). Oxytocin receptor genetic variation relates to empathy and stress reactivity in humans. Proceedings of the National Academy of Sciences, 106, 21437-21441.

Schneiderman, I., Kanat-Maymon, Y., Ebstein, R. P., \& Feldman, R. (2014). Cumulative risk on the oxytocin receptor gene (OXTR) underpins empathic communication difficulties at the first stages of romantic love. Social Cognitive and Affective Neuroscience, 9, 1524-1529.

Thompson, R. J., Parker, K. J., Hallmayer, J. F., Waugh, C. E., \& Gotlib, I. H. (2011). Oxytocin receptor gene polymorphism (rs2254298) interacts with familial risk for psychopathology to predict symptoms of depression and anxiety in adolescent girls. Psychoneuroendocrinology, 36, 144-147.

Tost, H., Kolachana, B., Hakimi, S., Lemaitre, H., Verchinski, B. A., Mattay, V. S., et al. (2010). A common allele in the oxytocin receptor gene (OXTR) impacts prosocial temperament and human 
hypothalamic-limbic structure and function. Proceedings of the National Academy of Sciences, 107, 13936-13941.

Tost, H., Kolachana, B., Verchinski, B. A., Bilek, E., Goldman, A. L., Mattay, V. S., et al. (2011). Neurogenetic effects of OXTR rs2254298 in the extended limbic system of healthy Caucasian adults. Biological Psychiatry, 70, e37-e39.

Van Ijzendoorn, M. H., \& Bakermans-Kranenburg, M. J. (2012). A sniff of trust: Meta-analysis of the effects of intranasal oxytocin administration on face recognition, trust to in-group, and trust to out-group. Psychoneuroendocrinology, 37, 438-443.

Weyant, J. M. (2007). Perspective taking as a means of reducing negative stereotyping of individuals who speak English as a second language. Journal of Applied Social Psychology, 37, 703-716.

White, H. R., Fleming, C. B., Kim, M. J., Catalano, R. F., \& McMorris, B. J. (2008). Identifying two potential mechanisms for changes in alcohol use among college-attending and non-collegeattending emerging adults. Developmental Psychology, 44, 1625-1639.

$\mathrm{Wu}, \mathrm{N} ., \mathrm{Li}, \mathrm{Z} .$, \& Su, Y. (2012). The association between oxytocin receptor gene polymorphism (OXTR) and trait empathy. Journal of Affective Disorders, 138, 468-472. 